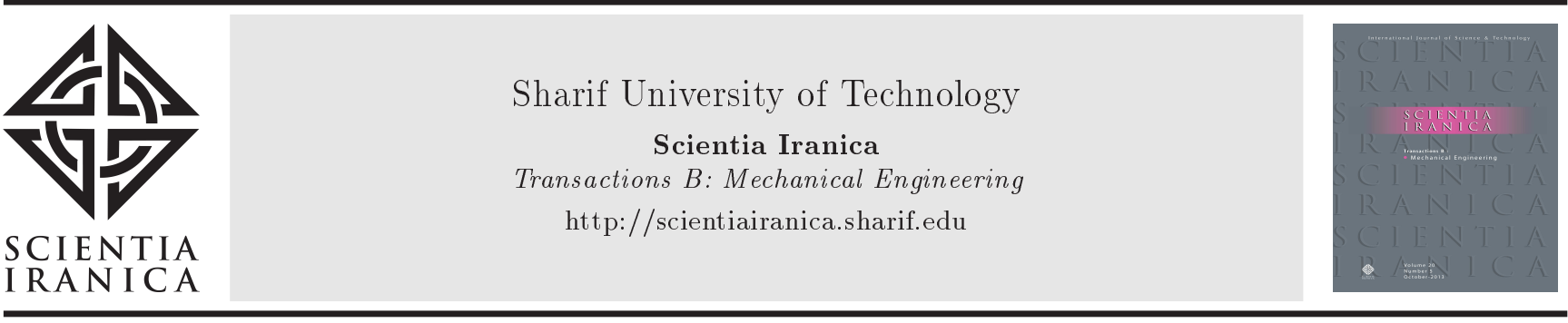

\title{
Effect of thermal radiation on magneto-nanofluids free convective flow over an accelerated moving ramped temperature plate
}

\author{
S.M. Hussain ${ }^{a, *}$, J. Jain ${ }^{b}$, G.S. Seth ${ }^{c}$, and M.M. Rashidi ${ }^{d}$ \\ a. Department of Mathematics, O.P. Jindal University, Raigarh (C.G.), India. \\ b. Department of Applied Mathematics, Government Engineering College, Bastar (C.G.), India. \\ c. Department of Applied Mathematics, Indian Institute of Technology (ISM), Dhanbad, India. \\ d. Shanghai Key Lab of Vehicle Aerodynamics and Vehicle Thermal Management System, Tongji University, Shanghai-201804, \\ China.
}

Received 26 September 2016; received in revised form 29 December 2016; accepted 22 April 2017

\section{KEYWORDS}

Nanofluid;

Inclined magnetic

field;

Thermal radiation;

Ramped temperature.

\begin{abstract}
An attempt has been made to explore the effect of thermal radiation on electrically conducting viscous, incompressible magnetonanofluids free convective flow in the presence of an inclined magnetic field. Fluid flow is persuaded due to accelerated movement of an infinite vertical ramped temperature plate. The water based nanofluids with nanoparticles of alumina $\left(\mathrm{Al}_{2} \mathrm{O}_{3}\right)$, copper $(\mathrm{Cu})$, and titanium oxide $\left(\mathrm{TiO}_{2}\right)$ have been accounted for. In order to mathematically model the problem, the model of nanoparticle volume fraction has been employed. The exact solution to the mathematical model in closed form has been analytically obtained by making use of Laplace transform technique. The amalgamated - form expressions are obtained for nanofluid velocity, nanofluid temperature, skin friction, and Nusselt number in both ramped and isothermal conditions. The effects of various physical parameters on the nanofluid velocity and nanofluid temperature have been examined by means of various graphs while the numerical values of skin friction and Nusselt number have been reported in different tables. The numerical results have been compared for both ramped and isothermal conditions. It has been noticed that both nanofluid velocity and nanofluid temperature are smaller in magnitude in the case of ramped temperature plate than in the case of isothermal plate.
\end{abstract}

(C) 2018 Sharif University of Technology. All rights reserved.

\section{Introduction}

In recent times, owing to the widespread applications in industry and public domain, the investigation of nanofluids has attracted continual interest of several researchers working in the area of nanotechnology. Nanofluids are the colloidal suspensions of nanoparti-

*. Corresponding author. Tel.: +917828240750 E-mail address: hussain.modassir@yahoo.com (S.M. Hussain)

doi: $10.24200 /$ sci. 2017.4333 cles of metals having diameters less than 100 nanometers in the base fluids, e.g. water, polymer solutions, ethylene glycol, oils, and other lubricants. Normally, the base fluids do not have adequate thermal conductivity for some practical applications. Therefore, the nanoparticles of metal are assorted with the base fluid to augment the thermal conductivity as the thermal conductivity of metals is higher than that of the base fluid. Nanofluids possess the augmented thermo-physical characteristics of thermal conductivity, viscosity, and thermal diffusivity and their unique properties make them tremendously helpful in different processes of heat transfer, e.g. in microelectronics, au- 
tomobiles, hybridpowered engines, fuel cells, domestic refrigerator, nuclear reactor coolant, pharmaceutical processes, etc. Choi [1] was the first who anticipated that the thermal conductivity of base fluid could be radically augmented by the uniform dispersion of nano sized metals in the fluid and such fluid was termed nanofluid. This thought inclined many researchers towards nanofluids, and abundant theoretical or experimental research for analyzing the thermal properties of nanofluids has been reported. A number of investigations conducted in the past have revealed that different factors, such as base fluid material, particle material, particle shape, particle size, particle volume fraction, particle clustering, nanoparticle base fluid interfacial layer, and nanoparticle Brownian motion and temperature, affect thermal conductivity of the nanofluids. Notable research investigations reporting the augmentation of thermal conductivity of fluid due to suspension of nanoparticles of metal in the fluid and its frequent applications have been reported by [2-16]

Several natural phenomena involved with the solutions to scientific and engineering problems demand the magnetohydrodynamic analysis, because the universe is occupied with extensively charged particles and infused by magnetic fields. In addition to this, the orientation and intensity of the exerted magnetic field strongly affect the behavior of flow. This is due to the fact that the suspended particles are manipulated by the applied magnetic field, resulting in the rearrangement of their concentration in the flow and, thereby, enhancing the heat transfer properties of the flow. The magneto nanofluids possess both the liquid and magnetic characteristics and are known to have mesmerizing applications in magnetooptical wavelength filters, optical modulators, ink float separation, optical switches, nonlinear optical materials, optical gratings, etc. Magneto nanofluids have wide applications in drug delivery for cancer treatment, as they play a significant role in guiding the drug particles up the blood stream to a tumor, because the magnetic nanoparticles are known to be more adhesive to tumor cells than to nonmalignant cells. The magneto nanofluids are also known to have applications in the treatment of magnetic cell separation, hyperthermia, and contrast enhancement in magnetic resonance imaging. Following this, several researchers reported their investigations into the problems of convective flow of nanofluids considering different geometries and configurations under influence of applied magnetic field. Hamad and Pop [17] theoretically studied the unsteady free convective nanofluid flow over an oscillatory moving vertical permeable flat plate under the influence of constant heat source and magnetic field in a rotating frame of reference. Chamkha and Aly [18] discussed the twodimensional steady magnetohydrodynamic free convective boundarylayer nanofluid flow of an incompressible pure base fluid suspended with nanoparticles over semi-infinite vertical permeable plate in the presence of magnetic field, heat generation, or absorption, thermophoresis, and Brownian diffusion effects. They concluded that the local skinfriction coefficient could be increased by increase in suction/injection parameter, Lewis number, thermophoresis parameter, heat generation, or absorption parameter, whereas it could be reduced by increasing the values of Brownian motion parameter, buoyancy ratio, and magnetic parameter. Sheikholeslami et al. [19] studied hydromagnetic laminar flow of a nanofluid embedded in a semiporous channel under the influence of transverse magnetic field. Das [20] explored the heat transfer characteristics of unsteady hydromagnetic free convective flow of an electrically conducting, viscous, and incompressible nanofluid past a semi-infinite vertical permeable moving plate in a porous medium taking into consideration the effects of thermal buoyancy force and constant heat source. He found that the nanofluid velocity got retarded in the boundary layer region due to the increasing values of magnetic field parameter, rotation parameter, nanoparticle volume fraction, and suction parameter, whereas injection parameter and permeability parameter had a reverse effect on it. Sheikholeslami et al. [21] discussed the hydromagnetic free convective flow of $\mathrm{CuO}$-water based nanofluid and heat transfer characteristics in an enclosure, which was heated from below employing lattice Boltzmann method. They showed that increase in heat source length, nanoparticle volume fraction, and Rayleigh number led to increase in the Nusselt number, while it decreased on increasing the values of Hartmann number. Sheikholeslami et al. [22] made a numerical investigation into hydromagnetic free convective flow of nanofluid in an eccentric semiannulus, which revealed that the Nusselt number was reduced due to increase in the position of inner cylinder at high Rayleigh number. Sheikholeslami and Ganji [23] theoretically analyzed the problem of hydromagnetic flow of nanofluid in a permeable channel. They concluded that due to the increasing values of Reynolds number and nanoparticle volume fraction, the nanofluid velocity boundary layer thickness decreased, while it increased with increase in Hartmann number. Nandkyeolyar et al. [24] numerically explored the heat transfer characteristics of water based nanofluid due to the combined effects of homogeneous-heterogeneous reactions in the presence of an external magnetic field and internal heat generation, which demonstrated that influence of the magnetic field was to condense the flow and the species concentration, and to boost the fluid temperature. Moreover, Reddy and Chamkha [25] discussed the hydromagnetic free convective boundary layer flow with heat and mass transfer characteristics of nanofluid embedded in a porous medium over a vertical cone. 
The analysis of hydromagnetic free convective flow of $\mathrm{Al}_{2} \mathrm{O}_{3}$-water based nanofluid in an open cavity considering uniform thermal boundary condition in the presence of uniform heat absorption/generation was performed by Mahmoudi et al. [26]. Ellahi [27] used homotopy analysis method to examine the effect of magnetic field on nonNewtonian flow of nanofluid in a pipe. Recently, Hayat et al. [28] investigated the unsteady magnetohydrodynamic twodimensional squeezing flow of viscous and incompressible nanofluids confined between two parallel walls under the influence of Brownian motion and thermophoresis effects. During the course of investigations, they found that the nanofluid velocity was accelerated due to increase in the value of squeezing parameter, whereas the thermal buoyancy force reduced both fluid temperature and nanoparticle concentration. More recently, Dhanai et al. [29] discussed the effect of thermal slip on hydromagnetic mixed convective flow of nanofluid with heat transfer along an inclined cylinder taking into account the effects of thermophoresis, Brownian motion, and viscous dissipation. They concluded that increase in mass transfer parameter raised the rate of heat transfer, while increase in thermal slip parameter reduced it.

The engineering processes in nuclear power plants, gas turbines, missiles' reentry, space vehicles, rocket combustion, satellites, various propulsion devices of aircraft, gas cooled nuclear reactors, etc., take place at high temperatures, where thermal radiation acts an important role in the overall surface heat transfer. Nowadays, the depletion of conventional energy sources at a rapid pace has triggered the necessity to switch towards sustainable or renewable energy sources for largescale industrial applications. Solar energy, as we all know, is the major source of renewal energy and thermal radiation, can play a significant role in converting the solar energy into the form suitable for industrial applications. This fact has encouraged many researchers to take into account the effect of thermal radiation on hydromagnetic convective flow of nanofluids under different geometries and configurations. The effect of thermal radiation on unsteady natural convective flow with heat and mass transfer of nanofluids over a vertical infinite flat was investigated by Turkyilmazoglu and Pop [30]. Rashidi et al. [31] performed a numerical study to examine the effect of buoyancy force on hydromagnetic convective flow of a viscous and incompressible nanofluid past a stretching sheet in the presence of transverse magnetic field taking into account the effect of thermal radiation. The combined effect of slip and thermal radiations on hydromagnetic stagnation point flow of nanofluid past a stretching sheet was investigated by Haq et al. [32]. Das and Jana [33] investigated the magnetohydrodynamic free convective boundary layer flow of nanofluid over a moving vertical plate in the presence of transverse magnetic field taking into consideration the effect of thermal radiation. They solved the governing equations using Laplace transform technique and concluded that both nanofluid velocity and temperature were reduced due to increase in radiation parameter. Subsequently, Das et al. [34] discussed the unsteady hydromagnetic free convection boundary layer flow of an electrically conducting and radiating nanofluid over an infinite porous plate in a rotating frame of reference with uniform suction or blowing at the plate. They observed that radiation parameter had the tendency to enhance both the nanofluid velocity and fluid temperature; however, both were reduced due to the suction velocity. Sheikholeslami et al. [35] numerically studied the influence of thermal radiation on steady hydromagnetic incompressible nanofluid flow confined between two horizontal rotating plates taking into consideration the effects of Brownian motion and thermophoresis. They concluded that increase in radiation parameter and Reynolds number led to decrease in temperature boundary layer thickness, while with increase in the values of other physical parameters, it increased. Nusselt number is enhanced by increase in radiation parameter and Reynolds number, where it is reduced with increase in the values of Schmidt number, rotation, Brownian, thermophoretic, and magnetic parameters. Sheikholeslami et al. [36] used Control Volume based Finite Element Method (CVFEM) to analyze the combined effect of Ferro Hydro Dynamic (FHD) and Magneto Hydro Dynamic (MHD) on ferrofluid flow with heat transfer in a semi annulus enclosure considering thermal radiation into account. Ellahi et al. [37] investigated the simultaneous effects of magnetic field, thermal radiation, and power law index on the free convective boundary layer flow of $\mathrm{Cu}-$ water based nanofluid along an inverted cone. Zeeshan et al. [38] analyzed the thermal radiation and heat transfer effects on the ferromagnetic fluid flowing over a stretching sheet. Recently, Das et al. [39] studied the effects of thermal radiation on unsteady free convection flow of a viscous and incompressible nanofluid in a vertical channel using the Laplace transform technique. Subsequently, Das et al. [40] explored the effect of thermal radiation on MHD free convective flow of nanofluid over an oscillating porous flat plate with Hall effects in a rotating frame of reference.

In all the aforementioned investigations, the solutions were obtained by assuming simplified conditions, where velocity and temperature at the plate were continuous and defined. But, majority of the problems of practical interest require velocity and temperature to satisfy nonuniform, discontinuous, or arbitrary conditions at the plate. Due to this, several researchers have investigated the problems of convective flow over a moving plate considering the ramped temperature, e.g. the works of Chandran et al. [41], Seth et al. [42- 
44], Nandkyeolyar et al. [45], and Hussain et al. [46,47]. Nandkeolyar et al. [48] investigated the problem of unsteady magnetohydrodynamic free convective flow of an electrically conducting, viscous, and incompressible nanofluid over an impulsively moving vertical plate with ramped temperature in the presence of thermal radiation effect. Recently, Khalid et al. [49] obtained the exact solutions for natural convective flow of nanofluid past an oscillating moving vertical plate with ramped temperature, using Laplace transform technique. In most of the above studies, the magnetic field is applied in the perpendicular direction to flow; but in problems of practical interest, such as MHD power generation, magnetic material processing flow control, and other geophysical problems, the magnetic field may act obliquely to the fluid flow. Ghosh and Bhattacharjee [50] investigated the steady MHD fully developed flow confined within a parallel plate channel with Hall effects in a rotating environment considering the inclined magnetic field. Ghosh et al. [51] studied the unsteady hydromagnetic free and forced convective flows in a rotating channel subject to forced oscillation under the influence of an inclined magnetic field. Recently, the effect of thermal radiation on unsteady hydromagnetic free convection flow of an optically thick radiating fluid past an impulsively moving vertical plate with ramped temperature embedded in a fluid saturated porous medium in the presence of inclined magnetic field was discussed by Nandkeolyar and Das [52].

The purpose of the present study is to examine the effect of thermal radiation on electrically conducting, viscous, incompressible, and time-dependent free convective flow of magnetonanofluids over an accelerated moving vertical ramped temperature plate under the influence of an inclined magnetic field. It is expected that the present findings will be useful in biological and physical sciences, electronics cooling, national security, transportation, and the environment.

\section{Mathematical analysis}

\subsection{Problem formulation and its solution}

Let us consider the time-dependent hydromagnetic free convective flow of an electrically conducting, viscous, incompressible, and optically thick radiating nanofluid under the influence of an inclined magnetic field as shown in Figures 1(a) and 1(b). Fluid flow is induced due to uniformly accelerated movement of an infinite vertical ramped temperature plate. The fluid flow is considered in the $x^{\prime}$ direction, taken along length of the plate in upward direction, and $y^{\prime}$ axis is normal to it. A uniform external magnetic field, $B_{0}$, is imposed in a direction that makes an angle, $\theta$, with the positive direction of $x^{\prime}$ axis. At first, i.e. at time $t^{\prime} \leq 0$, both the fluid and plate are at rest and preserved at

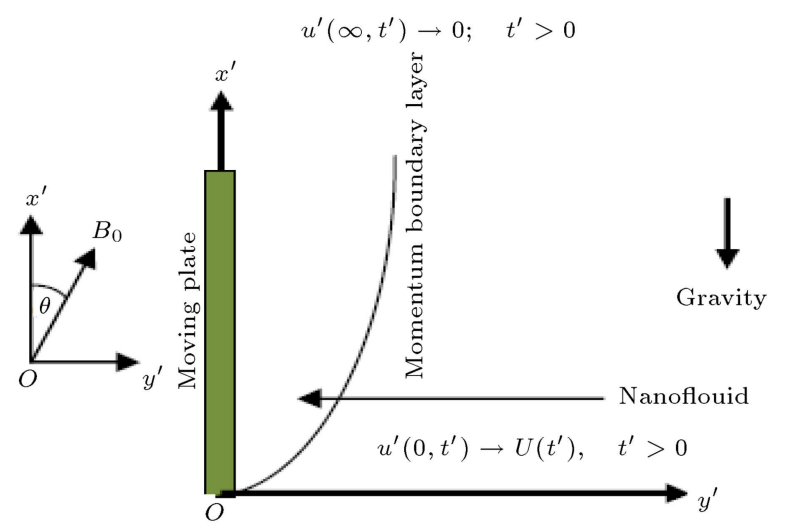

Figure 1(a). Physical model of the problem with momentum boundary layer.

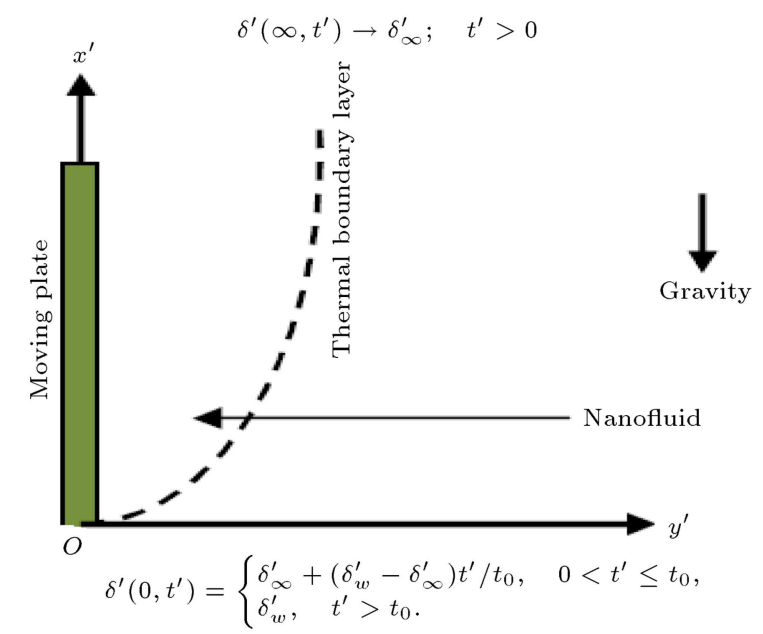

Figure 1(b). Physical model of the problem with thermal boundary layer.

uniform temperature, $\delta_{\infty}^{\prime}$. Then, at time $t^{\prime}>0$ the plate is set to move in the $x^{\prime}$ direction aligned with the gravitational field with time-dependent velocity $\Delta\left(t^{\prime}\right)$. Immediately, the temperature of the plate is raised or lowered to $\delta_{\infty}^{\prime}+\left(\delta_{w}^{\prime}-\delta_{\infty}^{\prime}\right) t^{\prime} / t_{0}$. Subsequently, at time $t^{\prime}>t_{0}$, the plate is maintained at uniform temperature, $\delta_{w}^{\prime}$. The water based nanofluid is considered, which contains 3 types of nanoparticles of $\mathrm{Cu}, \mathrm{Al}_{2} \mathrm{O}_{3}$, and $\mathrm{TiO}_{2}$. The nanoparticles are assumed to have uniform shape and size. Moreover, it is assumed that both the base fluid and the nanoparticles are in thermal equilibrium state and no slip takes place between them. The thermo physical characteristics of base fluid and nanoparticles are provided in Table 1 . The plate is assumed to be of infinite extent in $x^{\prime}$ direction and is electrically nonconducting. All physical quantities, except pressure, are only the functions of $y^{\prime}$ and $t^{\prime}$. Since the magnetic Reynolds number of the flow is taken to be very small, the induced magnetic field is neglected; therefore, magnetic field is $\vec{B} \equiv\left(B_{0} \cos \theta, B_{0} \sin \theta, 0\right)$. It is also assumed that the external electric field is zero and the electric field due to polarization of charges is 
Table 1. Thermophysical properties of water and nanoparticles [53].

\begin{tabular}{ccccccc}
\hline & $\begin{array}{c}\boldsymbol{\rho} \\
\left(\mathbf{k g} / \mathbf{m}^{3}\right)\end{array}$ & $\begin{array}{c}\boldsymbol{c}_{\boldsymbol{p}} \\
(\mathbf{J} / \mathbf{k g K})\end{array}$ & $\begin{array}{c}\boldsymbol{K} \\
(\mathbf{W} / \mathbf{m K})\end{array}$ & $\begin{array}{c}\boldsymbol{\beta} \times \mathbf{1 0}^{\mathbf{5}} \\
\left(\mathbf{K} \mathbf{1}^{-\mathbf{1}}\right)\end{array}$ & $\boldsymbol{\phi}$ & $\begin{array}{c}\boldsymbol{\sigma} \\
(\mathbf{S} / \mathbf{m})\end{array}$ \\
\hline Water (base fluid) & 997.1 & 4179 & 0.613 & 21 & 0.00 & $5.5 \times 10^{6}$ \\
$\mathbf{C u}$ (copper) & 8933 & 385 & 401 & 1.67 & 0.05 & $59.6 \times 10^{6}$ \\
$\mathbf{A l}_{\mathbf{2}} \mathbf{O}_{\mathbf{3}}$ (alumina) & 3970 & 765 & 40 & 0.85 & 0.15 & $35 \times 10^{6}$ \\
$\mathbf{T i O}_{\mathbf{2}}$ (Titanium oxide) & 4250 & 686.2 & 8.9538 & 0.90 & 0.20 & $2.6 \times 10^{6}$ \\
\hline
\end{tabular}

negligible, i.e. $\vec{E} \equiv(0,0,0)$. This corresponds to the case where no energy is added to or extracted from the fluid by electrical means.

Under the abovementioned assumptions and Boussinesq approximation, the mathematical model for the time-dependent free convective flow of an electrically conducting, viscous, and incompressible magnetonanofluid under the influence of an inclined magnetic field, taking thermal radiation into account, is reduced to:

$$
\begin{gathered}
\rho_{n f} \frac{\partial u^{\prime}}{\partial t^{\prime}}=\mu_{n f} \frac{\partial^{2} u^{\prime}}{\partial y^{\prime 2}}-\sigma_{n f} B_{0}^{2} \sin ^{2} \theta u^{\prime} \\
+g(\rho \beta)_{n f}\left(\delta^{\prime}-\delta^{\prime}{ }_{\infty}\right), \\
\left(\rho c_{p}\right)_{n f} \frac{\partial \delta^{\prime}}{\partial t^{\prime}}=k_{n f} \frac{\partial^{2} \delta^{\prime}}{\partial y^{\prime 2}}-\frac{\partial q_{r}^{\prime}}{\partial y^{\prime}} .
\end{gathered}
$$

For the nanofluids, the expressions for $\rho_{n f}, \mu_{n f}, \sigma_{n f}$, $(\rho \beta)_{n f}$, and $\left(\rho c_{p}\right)_{n f}$ are given as $[10,33,34,49]$ :

$$
\begin{aligned}
& \rho_{n f}=(1-\phi) \rho_{f}+\phi \rho_{s}, \mu_{n f}=\mu_{f}(1-\phi)^{-2.5}, \\
& (\rho \beta)_{n f}=(1-\phi)(\rho \beta)_{f}+\phi(\rho \beta)_{s}, \\
& \left(\rho c_{p}\right)_{n f}=(1-\phi)\left(\rho c_{p}\right)_{f}+\phi\left(\rho c_{p}\right)_{s}, \\
& \sigma_{n f}=\sigma_{f}\left[1+\frac{3(\sigma-1) \phi}{(\sigma+2)-(\sigma-1) \phi}\right] \\
& \sigma=\frac{\sigma_{s}}{\sigma_{f}} .
\end{aligned}
$$

The expressions presented in Eq. (3) are limited to spherical nanoparticles and are not valid for other shapes of nanoparticles [53-54]. The model for effective thermal conductivity of the nanofluid, i.e. $k_{n f}$, for the spherical nanoparticles given by Hamilton and Crosser model, followed by Oztop and Abu-Nada [53] and Kakac and Pramuanjaroenkij [55], is expressed as:

$$
k_{n f}=k_{f}\left[\frac{k_{s}+2 k_{f}-2 \phi\left(k_{f}-k_{s}\right)}{k_{s}+2 k_{f}+\phi\left(k_{f}-k_{s}\right)}\right] \text {. }
$$

Initial and boundary conditions for the nanofluid flow problem are:

$$
\begin{aligned}
& u^{\prime}=0, \delta^{\prime}=\delta_{\infty}^{\prime} \quad \text { for } \quad y^{\prime} \geq 0 \text { and } t^{\prime} \leq 0, \\
& u^{\prime}=\Delta\left(t^{\prime}\right) \text { at } y^{\prime}=0 \text { for } t^{\prime}>0
\end{aligned}
$$

$$
\begin{aligned}
& \delta^{\prime}=\delta_{\infty}^{\prime}+\left(\delta_{w}^{\prime}-\delta_{\infty}^{\prime}\right) t^{\prime} / t_{0} \\
& \text { at } y^{\prime}=0 \text { for } 0<t^{\prime}<t_{0}, \\
& \delta^{\prime}=\delta_{w}^{\prime} \text { at } y^{\prime}=0 \text { for } t^{\prime}>t_{0}, \\
& u^{\prime} \rightarrow 0, \delta^{\prime} \rightarrow \delta_{\infty}^{\prime} \text { as } y^{\prime} \rightarrow \infty \text { for } t^{\prime}>0
\end{aligned}
$$

For an optically thick radiating fluid, in addition to emission, there is self-absorption and, usually, the absorption coefficient is wavelength-dependent and large. Therefore, we can employ the Rosseland approximation for the radiative heat flux. The expression for radiative heat flux for an optically thick mediaadopting Rosseland approximation [56] is given by:

$$
q_{r}^{\prime}=-\frac{4 \sigma^{*}}{3 k^{*}} \frac{\partial \delta^{\prime 4}}{\partial y^{\prime}}
$$

where $k^{*}$ is the mean absorption co-efficient and $\sigma^{*}\left(=5.67 \times 10^{-8} \mathrm{~W} / \mathrm{m}^{2} \mathrm{~K}^{4}\right)$ is the Stefan-Boltzmann constant. We assume that the difference between the fluid temperature, $\delta^{\prime}$, in the boundary layer region and fluid temperature, $\delta_{\infty}^{\prime}$, in the free stream is sufficiently small so that Eq. (6) can be linearized by expanding $\delta^{\prime 4}$ in Taylor series about free stream temperature, $\delta_{\infty}^{\prime}$, which, after neglecting the second and higher order terms, takes the form:

$$
\delta^{\prime 4} \cong 4{\delta^{\prime}}_{\infty}^{3} \delta^{\prime}-3{\delta^{\prime}}_{\infty}^{4}
$$

Using Eqs. (6) and (7) in Eq. (2), we obtain:

$$
\left(\rho c_{p}\right)_{n f} \frac{\partial \delta^{\prime}}{\partial t^{\prime}}=\left(k_{n f}+\frac{16 \sigma^{*}{\delta^{\prime}}_{\infty}^{3}}{3 k^{*}}\right) \frac{\partial^{2} \delta^{\prime}}{\partial y^{\prime 2}} .
$$

In order to convert Eqs. (1) and (8) in dimensionless form, the following dimensionless variables and parameters are introduced:

$$
y=\frac{y^{\prime}}{U_{0} t_{0}}, u=\frac{u^{\prime}}{U_{0}}, t=\frac{t^{\prime}}{t_{0}}, \delta=\frac{\left(\delta^{\prime}-\delta^{\prime}{ }_{\infty}\right)}{\left(\delta^{\prime}{ }_{w}-\delta_{\infty}^{\prime}\right)} .
$$

Eqs. (1) and (9), in dimensionless form, are reduced to:

$$
\begin{aligned}
& \frac{\partial u}{\partial t}=a_{1} \frac{\partial^{2} u}{\partial y^{2}}-a_{2} M^{2} \sin ^{2} \theta u+a_{3} G r \delta \\
& \frac{\partial \delta}{\partial t}=\frac{1}{\alpha_{2}} \frac{\partial^{2} \delta}{\partial y^{2}}
\end{aligned}
$$


where:

$$
\begin{aligned}
& \phi_{1}=\left[(1-\phi)+\phi\left(\frac{\rho_{s}}{\rho_{f}}\right)\right], \\
& \phi_{2}=\left[1+\frac{3(\sigma-1) \phi}{(\sigma+2)-(\sigma-1) \phi}\right], \quad \sigma=\frac{\sigma_{s}}{\sigma_{f}}, \\
& \phi_{3}=\left[(1-\phi)+\phi \frac{\left(\rho \beta_{s}\right)}{\left(\rho \beta_{f}\right)}\right], \\
& \phi_{4}=\left[(1-\phi)+\phi \frac{\left(\rho c_{p}\right)_{s}}{\left(\rho c_{p}\right)_{f}}\right], \\
& a_{1}=\frac{1}{(1-\phi)^{2.5} \phi_{1}}, \quad a_{2}=\frac{\phi_{2}}{\phi_{1}}, \quad a_{3}=\frac{\phi_{3}}{\phi_{1}}, \\
& \alpha_{1}=\frac{k_{n f}}{k_{f}}, M^{2}=\frac{\sigma_{f} B_{0}^{2} v_{f}}{\rho_{f} U_{0}^{2}}, \quad \operatorname{Pr}=\frac{\left(\rho v c_{p}\right)_{f}}{k_{f}}, \\
& \operatorname{Tr}=\left(\frac{16 \sigma^{*} \delta_{\infty}^{3}}{3 k^{*} k_{f}}\right), \quad \mathrm{Gr}^{3}=\left[\frac{g \beta_{f} v_{f}\left(\delta_{w}^{\prime}-\delta_{\infty}^{\prime}\right)}{U_{0}^{3}}\right], \\
& \alpha_{2}=\left[\frac{\operatorname{Pr} \phi_{4}}{\alpha_{1}+\operatorname{Tr}^{\prime}}\right],
\end{aligned}
$$

where $M^{2}, \operatorname{Pr}, \operatorname{Tr}$, and $\mathrm{Gr}$ are respectively the magnetic parameter, Prandtl number, thermal radiation parameter, and Grashof number, and $\phi_{i}(i=1,2,3,4)$ are the functions that depend on the thermo-physical properties of the base fluid and nanoparticles.

In the above non-dimensional process, the characteristic time, $t_{0}$, has been defined as $t_{0}=v_{f} / U_{0}^{2}$, where $U_{0}$ is characteristic velocity.

The initial and boundary conditions (5) in dimensionless form are reduced to:

$$
\begin{aligned}
& u=0, \quad \delta=0 \text { for } y \geq 0 \text { and } t \leq 0, \\
& u=\Delta(t) \quad \text { at } y=0 \text { for } t>0, \\
& \delta=t \quad \text { at } y=0 \text { for } 0<t \leq 1, \\
& \delta=1 \text { at } y=0 \text { for } t>1, \\
& u \rightarrow 0, \quad \delta \rightarrow 0 \text { as } y \rightarrow \infty \text { for } t>0,
\end{aligned}
$$

where $\Delta(t)=\Delta\left(t^{\prime}\right) / U_{0}$.

Eqs. (10) and (11) together with the initial and boundary Conditions (13) correspond to fluid flow and are quite general; therefore, we have considered a particular case of interest, namely, uniformly accelerated movement of the plate, i.e. $\Delta(t)=\lambda t$ where $\lambda$ is dimensionless constant, to exploit the flow features of the fluid flow.

In order to obtain the exact solution, the set of dimensionless equations (Eqs. (10) and (11)) along with the initial and boundary Conditions (13) are analytically solved using Laplace transform technique; exact solutions for the nanofluid velocity, $u(y, t)$, and nanofluid temperature, $\delta(y, t)$, are obtained, which are expressed as follows:

$$
\begin{aligned}
u(y, t)= & \frac{\lambda}{2} f_{1}\left(y, a_{4}, a_{5}, 0, t\right) \\
& +\frac{\alpha_{3}}{2 \alpha_{4}}\left\{F_{1}(y, t)-H(t-1) F_{1}(y, t-1)\right\} \\
\delta(y, t)= & \delta_{1}(y, t)-H(t-1) \delta(y, t-1),
\end{aligned}
$$

where:

$$
\begin{aligned}
& a_{4}=1 / a_{1}, \quad a_{5}=M^{2} a_{2} \sin ^{2} \theta, \quad \alpha_{3}=G r a_{3} a_{4} /\left(\alpha_{2}-a_{4}\right), \\
& \alpha_{4}=a_{4} a_{5} /\left(\alpha_{2}-a_{4}\right), \\
& F_{1}(y, t)=\frac{e^{\alpha_{4} t}}{\alpha_{4}}\left\{f_{2}\left(y, a_{4}, a_{5}, \alpha_{4}, t\right)-f_{2}\left(y, \alpha_{2}, 0, \alpha_{4}, t\right)\right\} \\
& -f_{1}\left(y, a_{4}, a_{5}, \alpha_{4}, t\right)-2 f_{3}\left(y, \alpha_{2}, \alpha_{4}, t\right), \\
& \delta_{1}(y, t)=f_{3}\left(y, \alpha_{2}, 0, t\right) .
\end{aligned}
$$

The expressions for $f_{i}(i=1,2,3)$ are presented in Appendix A.

\subsection{Solution for the case of isothermal plate}

The solutions presented by Eqs. (14) and (15) are for the nanofluid velocity and nanofluid temperature for the convective flow of an electrically conducting, viscous, incompressible, and optically thick radiating magneto-nanofluid over an accelerated moving vertical ramped temperature plate in the presence of inclined magnetic field. In order to analyze the effect of ramped temperature on the flowfield, it is worthwhile to compare such a flow with the one near an accelerated moving vertical plate with uniform temperature. Owing to the assumptions made in Section 2.1, the solutions for the nanofluid velocity and nanofluid temperature for free convective magneto-nanofluid flow over an accelerated moving vertical plate with isothermal condition are obtained and expressed as:

$$
\begin{aligned}
u(y, t)= & \frac{\lambda}{2} f_{1}\left(y, a_{4}, a_{5}, 0, t\right) \\
& +\frac{\alpha_{3}}{2 \alpha_{4}}\left[e ^ { \alpha _ { 4 } t } \left\{f_{2}\left(y, a_{4}, a_{5}, \alpha_{4}, t\right)\right.\right. \\
& \left.-f_{2}\left(y, \alpha_{2}, 0, \alpha_{4}, t\right)\right\}-f_{2}\left(y, a_{4}, 0, a_{5}, t\right) \\
& \left.+2 \operatorname{erfc}\left(\frac{y}{2} \sqrt{\frac{\alpha_{2}}{t}}\right)\right],
\end{aligned}
$$




$$
\delta(y, t)=\operatorname{erfc}\left(\frac{y}{2} \sqrt{\frac{\alpha_{2}}{t}}\right) .
$$

\subsection{Skin friction and Nusselt number}

The expressions for dimensionless skin friction, $\tau$, which measure the shear stress at the plate, and Nusselt number, $\mathrm{Nu}$, which measure the rate of heat transfer at the plate, are exhibited in the following forms for both ramped and isothermal conditions.

For the ramped condition:

$$
\begin{aligned}
& \tau=\frac{\lambda}{2} f_{4}\left(a_{4}, a_{5}, t\right)+\frac{\alpha_{3}}{\alpha_{4}}\left\{F_{2}(t)-H(t-1) F_{2}(t-1)\right\} \\
& \mathrm{Nu}=2 \sqrt{\frac{\alpha_{2}}{\pi}}\{\sqrt{t}-H(t-1) \sqrt{t-1}\}
\end{aligned}
$$

where:

$$
\begin{aligned}
F_{2}(t)= & \frac{e^{\alpha_{4} t}}{\alpha_{4}}\left\{f_{5}\left(a_{4}, a_{5}, \alpha_{4}, t\right)\right. \\
& \left.-f_{5}\left(\alpha_{2}, 0, \alpha_{4}, t\right)\right\}-\frac{1}{2}\left\{f_{4}\left(a_{4}, a_{5}, t\right)\right. \\
& \left.+4 \sqrt{\frac{\alpha_{2} t}{\pi}}\right\}-\frac{1}{\alpha_{4}}\left\{f_{5}\left(a_{4}, a_{5}, 0, t\right)+\sqrt{\frac{\alpha_{2}}{t \pi}}\right\},
\end{aligned}
$$

and, for isothermal plate:

$$
\begin{aligned}
\tau= & \frac{\lambda}{2} f_{4}\left(a_{4}, a_{5}, t\right) \\
& +\frac{\alpha_{3}}{\alpha_{4}}\left[e^{\alpha_{4} t}\left\{f_{5}\left(a_{4}, a_{5}, \alpha_{4}, t\right)-f_{5}\left(\alpha_{2}, 0, \alpha_{4}, t\right)\right\}\right. \\
& -f_{5}\left(a_{4}, a_{5}, 0, t\right)-\sqrt{\left.\frac{\alpha_{2}}{t \pi}\right]} \\
\mathrm{Nu} & =\sqrt{\frac{\alpha_{2}}{t \pi}} .
\end{aligned}
$$

Expressions for $f_{i}(i=4,5)$ are given in Appendix A.

\section{Results and discussion}

To explore the physical perspective of various dimensionless controlling parameters on flowfield, the numerical computations have been performed and the results for the nanofluid velocity and temperature have been elucidated by means of various graphs; moreover, for engineering perspective, the numerical values of skin friction and Nusselt number have been reported by different tables. Three types of waterbased nanofluids with the nanoparticles of copper $(\mathrm{Cu})$, alumina $\left(\mathrm{Al}_{2} \mathrm{O}_{3}\right)$, and titanium oxide $\left(\mathrm{TiO}_{2}\right)$ have been considered. The numerical values of $\mathrm{Cu}$ water based nanofluid velocity, $u(y, t)$, computed from the analytical solutions reported in Sections 2.1 and 2.2 , have been displayed by different graphs versus the boundary layer coordinate $y$ in Figures 2-7 for different values of magnetic parameter, $M^{2}$, angle of inclination of magnetic field, $\theta$, Grashof number, Gr, nanoparticle volume fraction, $\theta$, radiation parameter, $\operatorname{Tr}$, and time, $t$, taking Prandtl number $\operatorname{Pr}=6.2$ (for water) and $\lambda=1$. As suggested by Das et al. [34], the values of $\phi$ have been considered in the range of $0 \leq \phi \leq 0.2$. In addition, the spherical nanoparticles along with their dynamic viscosity and

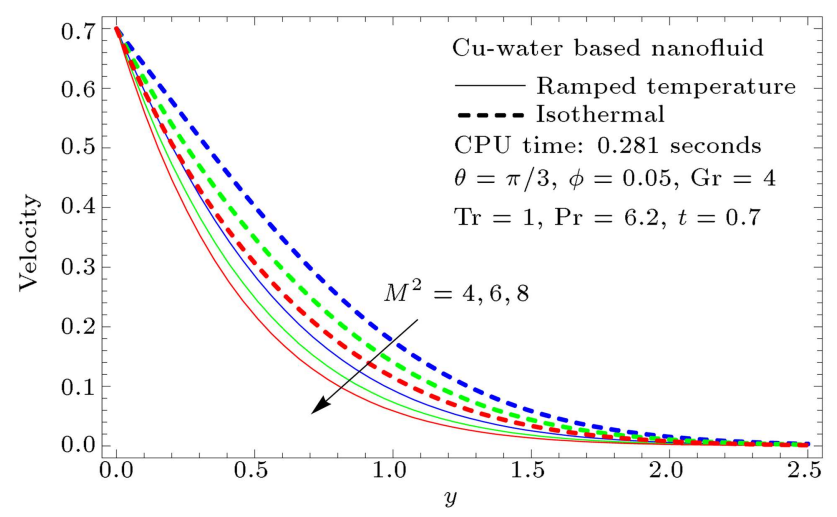

Figure 2. Effect of $M^{2}$ on velocity profiles.

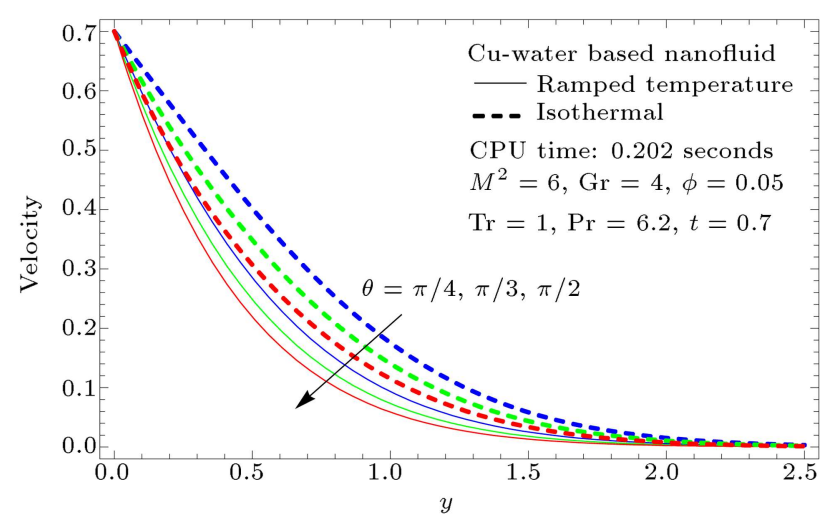

Figure 3. Effect of $\theta$ on velocity profiles.

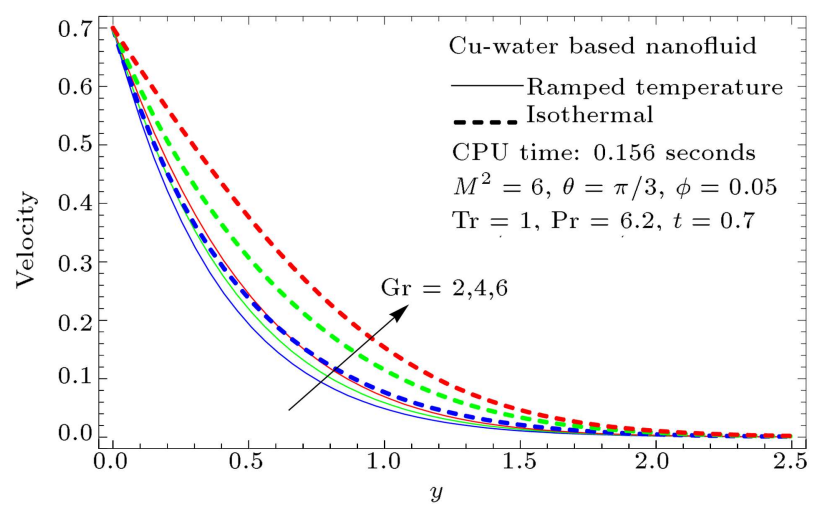

Figure 4. Effect of Gr on velocity profiles. 


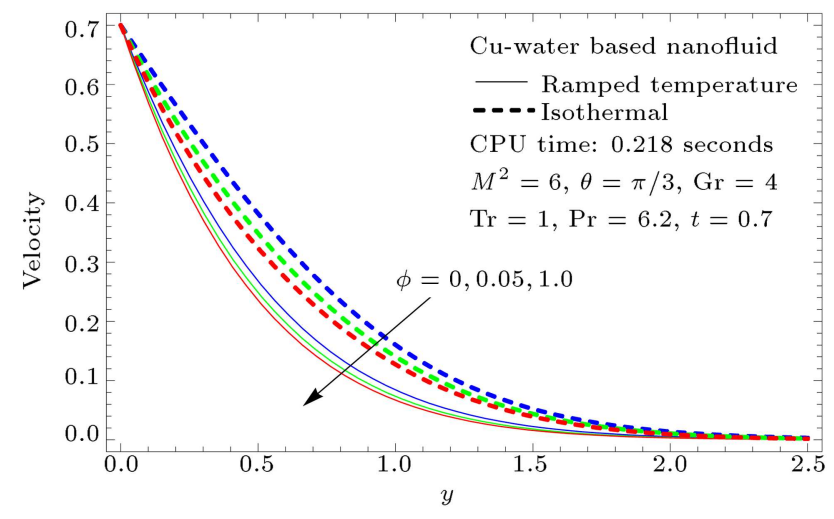

Figure 5. Effect of $\phi$ on velocity profiles.

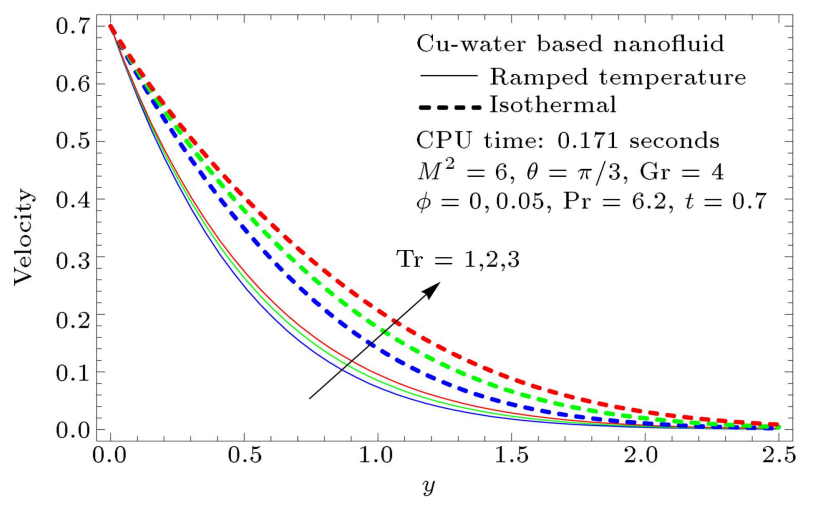

Figure 6. Effect of $\operatorname{Tr}$ on velocity profiles.

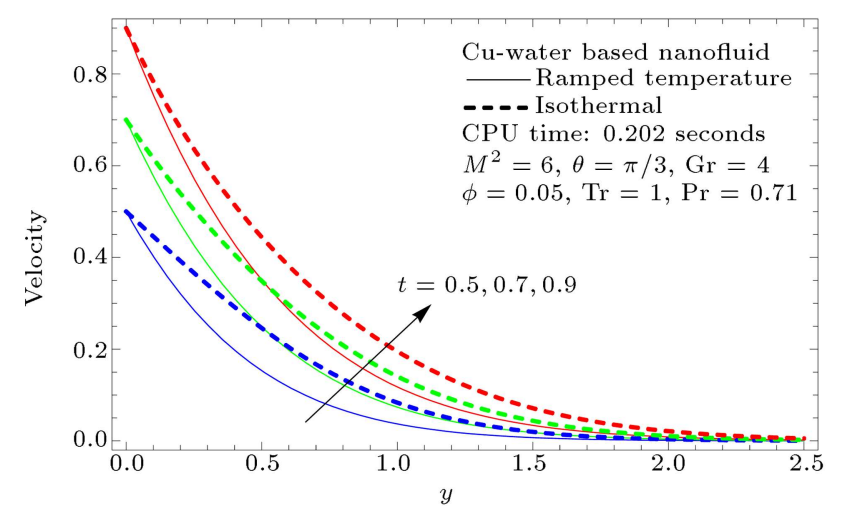

Figure 7. Effect of $t$ on velocity profiles.

thermal conductivity have been used, as mentioned in Table 1 . The values of other physical parameters and $\mathrm{CPU}$ time have been provided in the respective figures. It is observed in Figures 2-7 that, for both isothermal and ramped conditions, the nanofluid velocity, $u(y, t)$, attains a maximum distinctive value near the surface of plate and, then, decreases properly on increasing the boundary layer coordinate $y$ to approach free stream value. This is due to the fact that the buoyancy force has momentous impact on the flow-field near the surface of plate and its consequence is nullified in the free stream. It is also observed that the nanofluid velocity is higher in magnitude in the case of isothermal plate than in ramped temperature plate. Figure 2 shows the influence of magnetic parameter, $M^{2}$, on the nanofluid velocity. It is revealed from Figure 2 that, for both isothermal and ramped conditions, increase in $M^{2}$ leads to slowdown in the nanofluid velocity. This is due to the fact that the presence of a magnetic field in an electrically conducting nanofluid introduces a resistive type body force, known as Lorentz force, which has propensity to slow down the fluid motion in the boundary layer region, thereby, requiring the application of an external magnetic field, a powerful mechanism for inhibiting the nanofluid motion, to maintain laminar flow characteristics. The effect angle of inclination of magnetic field, $\theta$, on the nanofluid velocity is shown in Figure 3. It is evident from Figure 3 that, for both isothermal and ramped conditions, the nanofluid velocity decreases on increasing the value of $\theta$ in the boundary layer region. This implies that, for both isothermal and ramped conditions, the angle of inclination of magnetic field has tendency to slow down the nanofluid velocity and the strength of resistive force is maximum when magnetic field is applied in the transverse direction to the fluid flow. It is well known that resistive force (Lorentz force) has tendency to suppress the fluid motion. If it is required to accelerate fluid flow in practical problems of interest, then, in the place of applying magnetic field in the vertical direction, it may be applied in another direction, which is similar to the direction of the flow. Therefore, by changing the angle of inclination of the applied magnetic field, the nanofluid velocity may be accelerated or retarded. Figure 4 depicts the effect of Grashof number, Gr, on the nanofluid velocity. It is revealed from Figure 4 that, for both isothermal and ramped conditions, the nanofluid velocity increases with increase in $\mathrm{Gr}$ in the boundary layer region. This implies that thermal buoyancy force has accelerating influence on the nanofluid velocity for both isothermal and ramped conditions in the boundary layer region. This phenomenon can be attributed to the fact that the positive values of Grashof number behave like a flattering pressure gradient, which accelerate the fluid flow in the boundary layer region. The effect of volume fraction of nanoparticles, $\phi$, on the nanofluid velocity is presented by Figure 5. It is observed from Figure 5 that, for both isothermal and ramped conditions, as $\phi$ increases, the nanofluid velocity decreases in the boundary layer region due to increase in viscosity. This implies that the nanoparticle volume fraction tends to retard the nanofluid velocity for both isothermal and ramped conditions. Physically, this trend is because increase in the volume fraction of nanoparticle tends to reduce thermal conductivity of the nanofluid, which in turn causes reduction in the thickness of boundary layer and increase in the viscosity, thereby decreasing the nanofluid velocity. Figures 6 and 7 depict the 
influence of radiation parameter, $\mathrm{Tr}$, and time, $t$, on the nanofluid velocity. It is inferred from Figure 6 that the nanofluid velocity is accelerated on increasing the values of radiation parameter, $\mathrm{Tr}$, for both isothermal and ramped conditions. This implies that thermal radiation causes enrichment in the nanofluid velocity for both isothermal and ramped conditions. This fact is justified as increase in radiation parameter, Tr, results in the rise of fluid temperature, as observed in Figure 10, by virtue of which the thermal buoyancy force gets stronger. This increased thermal buoyancy force results in accelerated fluid motion. It is apparent in Figure 7 that there is increase in the nanofluid velocity on increasing time, $t$. This observation suggests that nanofluid velocity gets accelerated with the progress of time. Figure 8 shows the comparison of velocity profiles for different types of water-based nanofluids containing the nanoparticles of copper $(\mathrm{Cu})$, alumina $\left(\mathrm{Al}_{2} \mathrm{O}_{3}\right)$, and titanium oxide $\left(\mathrm{TiO}_{2}\right)$. It is revealed in Figure 8 that, for both isothermal and ramped conditions, $\mathrm{Cu}$-water based nanofluid has the highest velocity, followed by $\mathrm{Al}_{2} \mathrm{O}_{3}$-water and $\mathrm{TiO}_{2}$-water based nanofluids in the vicinity of the plate.

The effects of nanoparticle volume fraction $\phi$ radiation parameter, $\mathrm{Tr}$, and time, $t$, on the $\mathrm{Cu}$-water based temperature profiles are presented in Figures 9-

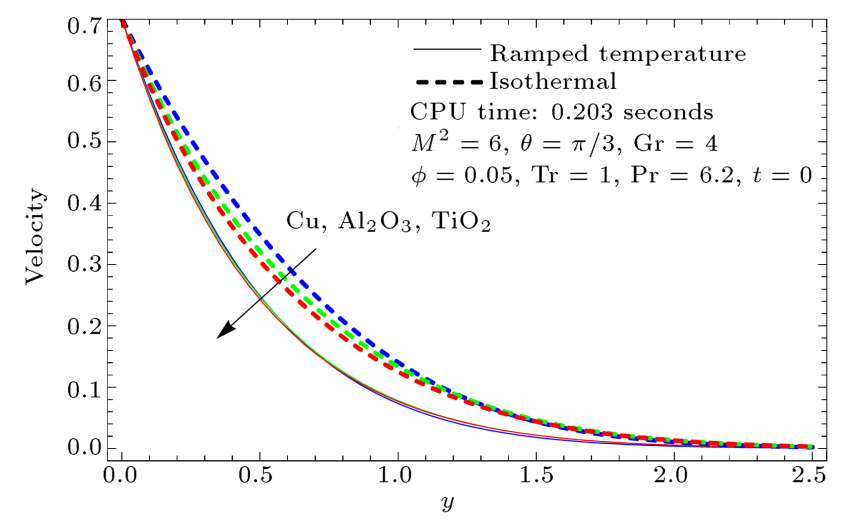

Figure 8. Comparison of velocity profiles for different nanofluids.

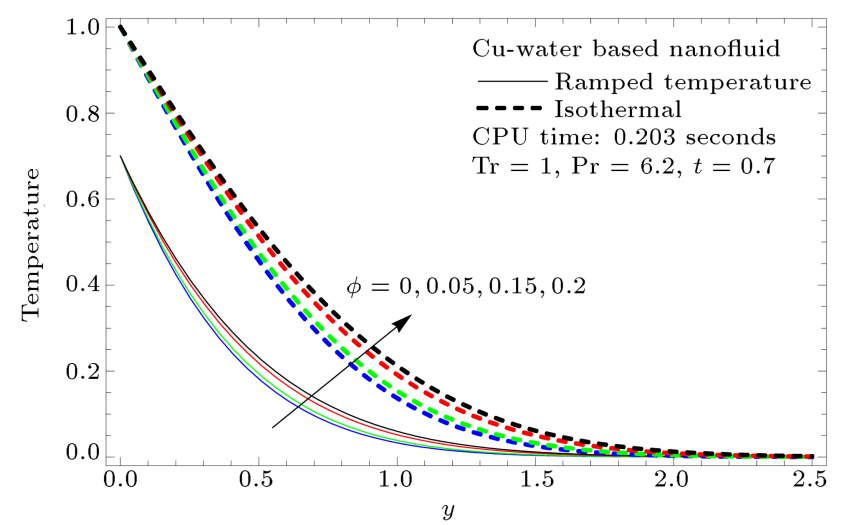

Figure 9. Effect of $\phi$ on temperature profiles.

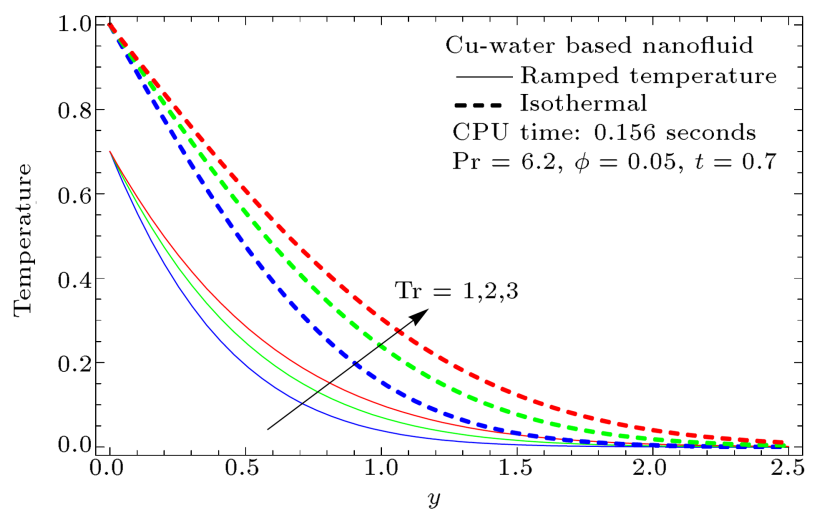

Figure 10. Effect of $\operatorname{Tr}$ on temperature profiles.

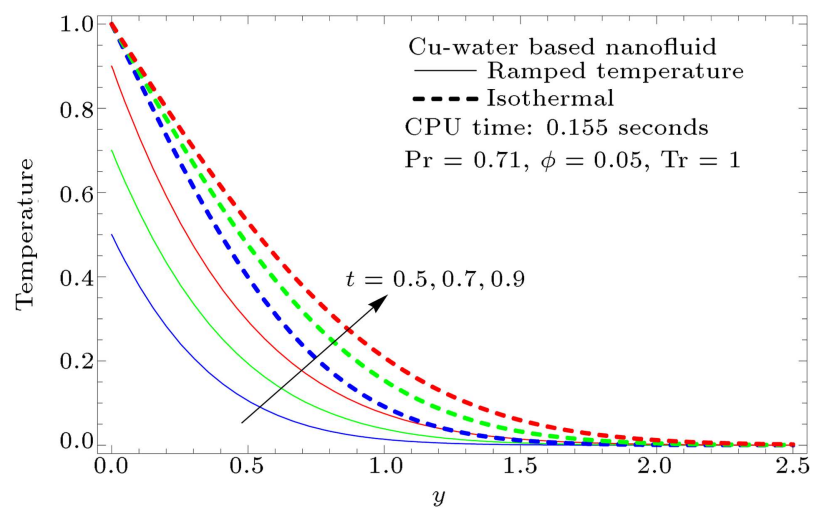

Figure 11. Effect of $t$ on temperature profiles.

11, considering Prandtl number, $\operatorname{Pr}=6.2$. It is observed from Figures 9-11 that, for both isothermal and ramped conditions, increase in either $\phi$ or Tr or $t$ results in significant rise in the nanofluid fluid temperature, $\delta(y, t)$. Physically, it is interpreted as the nanoparticles volume fraction and thermal radiation has tendency to increase the nanofluid temperature in the boundary layer region for both isothermal and ramped conditions. The temperature of nanofluid gets enhanced with the progress of time. The effect of thermal radiation on the nanofluid temperature is in agreement with its physical behavior in enhancing the conduction effect, resulting in the enhancement of the nanofluid temperature in the boundary layer region. The comparison of nanofluid temperature profiles in the cases of isothermal and ramped conditions for different nanofluids with the nanoparticles of $\mathrm{Cu}, \mathrm{Al}_{2} \mathrm{O}_{3}$, and $\mathrm{TiO}_{2}$ is depicted in Figure 12. It is apparent from Figure 12 that, for both isothermal and ramped conditions, the temperature of $\mathrm{TiO}_{2}$-water based nanofluid is higher in magnitude, followed by the temperature of $\mathrm{Al}_{2} \mathrm{O}_{3}$-water and $\mathrm{Cu}$ water based nanofluids.

The numerical values of dimensionless skin friction, $\tau$, of $\mathrm{Cu}$-water based nanofluid for both isothermal and ramped conditions, computed by Expressions (18) and (20), are presented by Table 2 for various values of $M^{2}, \theta, \mathrm{Gr}, \phi, \operatorname{Tr}$, and $t$, taking $\operatorname{Pr}=$ 
Table 2. Skin friction, $\tau$, for $\mathrm{Cu}$-water based nanofluid when $\operatorname{Pr}=6.2$.

\begin{tabular}{cccccccc}
\hline $\boldsymbol{M}^{\mathbf{2}}$ & $\boldsymbol{\theta}$ & $\mathbf{G r}$ & $\boldsymbol{\phi}$ & $\mathbf{T r}$ & $\boldsymbol{t}$ & $\begin{array}{c}-\boldsymbol{\tau} \\
\text { for ramped } \\
\text { temperature }\end{array}$ & $\begin{array}{c}-\boldsymbol{\tau} \\
\text { for isothermal } \\
\text { temperature }\end{array}$ \\
\hline $\mathbf{4}$ & $\pi / 3$ & 4 & 0.05 & 1 & 0.7 & 1.02378 & 0.58356 \\
$\mathbf{6}$ & $\pi / 3$ & 4 & 0.05 & 1 & 0.7 & 1.32006 & 0.89123 \\
$\mathbf{8}$ & $\pi / 3$ & 4 & 0.05 & 1 & 0.7 & 1.54135 & 1.14261 \\
6 & $\boldsymbol{\pi} / \mathbf{4}$ & 4 & 0.05 & 1 & 0.7 & 1.16180 & 0.73487 \\
6 & $\boldsymbol{\pi} / \mathbf{3}$ & 4 & 0.05 & 1 & 0.7 & 1.52590 & 0.92567 \\
6 & $\boldsymbol{\pi} / \mathbf{2}$ & 4 & 0.05 & 1 & 0.7 & 1.38488 & 1.15001 \\
6 & $\pi / 3$ & $\mathbf{2}$ & 0.05 & 1 & 0.7 & 1.57200 & 1.35759 \\
6 & $\pi / 3$ & $\mathbf{4}$ & 0.05 & 1 & 0.7 & 1.72006 & 0.89123 \\
6 & $\pi / 3$ & $\mathbf{6}$ & 0.05 & 1 & 0.7 & 1.06811 & 0.42488 \\
6 & $\pi / 3$ & 4 & $\mathbf{0 . 0 0}$ & 1 & 0.7 & 1.30779 & 0.71215 \\
6 & $\pi / 3$ & 4 & $\mathbf{0 . 0 5}$ & 1 & 0.7 & 1.52590 & 0.92567 \\
6 & $\pi / 3$ & 4 & $\mathbf{0 . 1 0}$ & 1 & 0.7 & 1.67369 & 1.08816 \\
6 & $\pi / 3$ & 4 & 0.05 & $\mathbf{1}$ & 0.7 & 1.52590 & 0.92567 \\
6 & $\pi / 3$ & 4 & 0.05 & $\mathbf{3}$ & 0.7 & 1.76739 & 0.79945 \\
6 & $\pi / 3$ & 4 & 0.05 & $\mathbf{5}$ & 0.7 & 1.88219 & 0.73140 \\
6 & $\pi / 3$ & 4 & 0.05 & 1 & $\mathbf{0 . 5}$ & 1.15726 & 0.63865 \\
6 & $\pi / 3$ & 4 & 0.05 & 1 & $\mathbf{0 . 7}$ & 1.52590 & 0.92567 \\
6 & $\pi / 3$ & 4 & 0.05 & 1 & $\mathbf{0 . 9}$ & 1.90807 & 1.26780 \\
\hline & & & & & & &
\end{tabular}

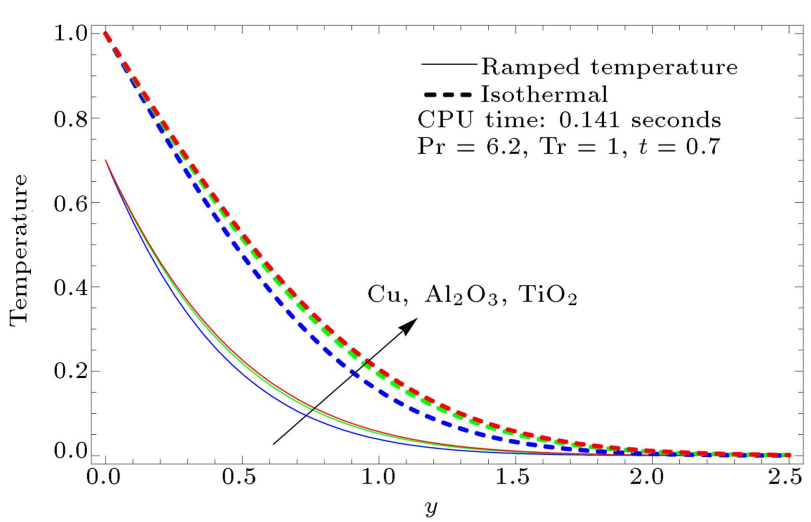

Figure 12. Comparison of temperature profiles for different nanofluids.

6.2 and $\lambda=1$; also, the values of Nusselt number $\mathrm{Nu}$, calculated by the expressions (19) and (21), are exhibited in Table 3 for different values of $\phi$, Tr, and $t$. It is observed from Table 2 that, for both isothermal and ramped conditions, skin friction, $\tau$, increases on increasing the values of $M^{2}, \theta, \phi$, and $t$. For ramped temperature plate, skin friction, $\tau$, increases whereas, for isothermal plate, it decreases on increasing the values of $\mathrm{Gr}$ and Tr. This implies that magnetic field, angle of inclination of magnetic field, and nanoparticle volume fraction tend to increase the shear stress at the plate for both isothermal and ramped conditions. The solutal buoyancy force and thermal radiation have tendency to increase the shear stress at the plate for the
Table 3. Nusselt number $\mathrm{Nu}$ for $\mathrm{Cu}$-water based nanofluid when $\operatorname{Pr}=6.2$.

\begin{tabular}{ccccc}
\hline $\boldsymbol{\phi}$ & $\mathbf{T r}$ & $\boldsymbol{t}$ & $\begin{array}{c}\mathrm{Nu} \\
\text { for ramped } \\
\text { temperature }\end{array}$ & $\begin{array}{c}\text { Nu } \\
\text { for isothermal } \\
\text { temperature }\end{array}$ \\
\hline $\mathbf{0 . 0 0}$ & 1 & 0.7 & 1.66221 & 1.18729 \\
$\mathbf{0 . 0 5}$ & 1 & 0.7 & 1.59352 & 1.13823 \\
$\mathbf{0 . 1 0}$ & 1 & 0.7 & 1.52596 & 1.08997 \\
0.05 & $\mathbf{1}$ & 0.7 & 1.59352 & 0.13001 \\
0.05 & $\mathbf{3}$ & 0.7 & 1.14789 & 0.12522 \\
0.05 & $\mathbf{5}$ & 0.7 & 0.94320 & 0.10505 \\
0.05 & 1 & $\mathbf{0 . 5}$ & 1.34677 & 0.11383 \\
0.05 & 1 & $\mathbf{0 . 7}$ & 1.59352 & 0.13001 \\
0.05 & 1 & $\mathbf{0 . 9}$ & 1.80688 & 0.15466 \\
\hline
\end{tabular}

ramped temperature plate, whereas both have reverse effect on it for the case of isothermal plate. The shear stress at the plate gets enhanced with the progress of time for both isothermal and ramped conditions. The Nusselt number $\mathrm{Nu}$ is the measure of rate of heat transfer at the plate. It is seen from Table 3 that, for isothermal and ramped conditions, an increase in either $\phi$ or $\operatorname{Tr}$ leads to decrease in the Nusselt number, $\mathrm{Nu}$, whereas it increases on increasing the values of $t$. This implies that, for isothermal and ramped conditions, the nanoparticles volume fraction and thermal radiation tend to reduce the rate of heat 


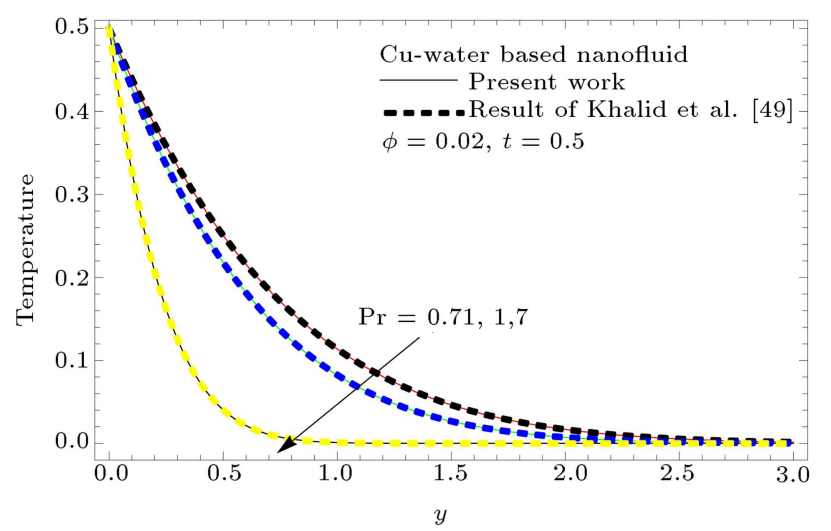

Figure 13. Comparison of temperature profiles with those reported by Khalid et al. [49].

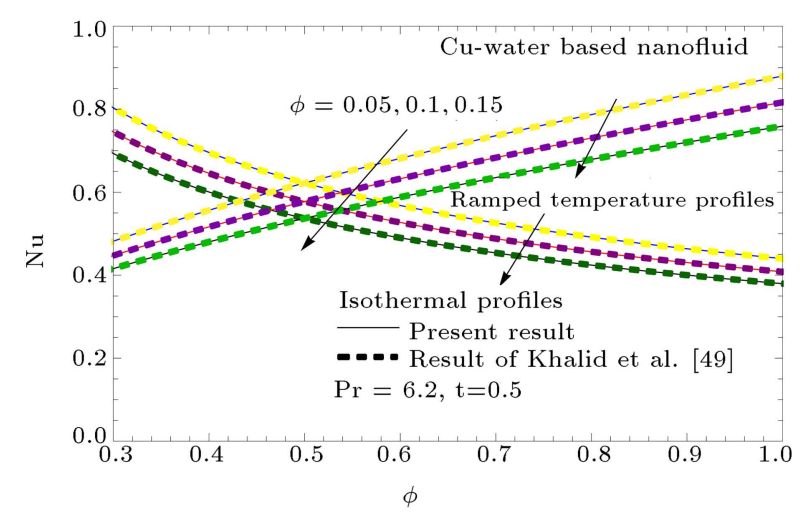

Figure 14. Comparison of Nusselt numbers with those reported by Khalid et al. [49].

transfer at the plate, whereas it gets improved with the progress of time.

\subsection{Validation of the results}

In order to validate the accuracy of results obtained in the present study, the profiles of temperature and Nusselt number have been compared with those reported by Khalid et al. [49], obtained under similar settings but in the absence of thermal radiation (i.e. $\operatorname{Tr}=0)$. Comparison reveals an excellent agreement between both the results as it is evident from Figures 13 and 14 .

\section{Conclusions}

The effect of thermal radiation on an electrically conducting, viscous, and incompressible time-dependent magneto-nanofluid free convective flow over an accelerated moving vertical plate under the influence of an inclined magnetic field with ramped temperature has been investigated. The important findings of the present study for both isothermal and ramped conditions are summarized below.

The nanofluid velocity is slowed down in the boundary layer region due to the augmentation of mag- netic parameter, angle of inclination of magnetic field, and nanoparticle volume fraction, whereas thermal buoyancy force and thermal radiation have tendency to speed up the velocity, which is accelerated with the progress of time. The $\mathrm{Cu}$-water based nanofluid has the highest velocity, followed by $\mathrm{Al}_{2} \mathrm{O}_{3}$-water and $\mathrm{TiO}_{2}$-water based nanofluids in the vicinity of the plate. The nanoparticles volume fraction and thermal radiation lead to rise in nanofluid temperature in the boundary layer region, which also gets augmented with the progress of time. The magnetic field, angle of inclination of magnetic field, and nanoparticle volume fraction tend to raise the shear stress at the plate. The nanoparticles volume fraction and thermal radiation tend to lessen the rate of heat transfer at the plate, although it is improved with the progress of time. The nanofluid velocity and temperature are smaller in magnitude in the case of ramped condition than in isothermal condition.

\section{Acknowledgment}

Authors are grateful to the reviewers for their valuable comments and suggestions, which helped them to improve the quality of the research paper.

\section{Nomenclature}

$g \quad$ Acceleration due to gravity $\left(\mathrm{ms}^{-2}\right)$

Gr Grashof number

$$
\left(g \beta_{f} v_{f}\left(\delta^{\prime}{ }_{w}-\delta^{\prime}{ }_{\infty}\right) / U_{0}^{3}\right.
$$

$k_{f} \quad$ Thermal conductivity of base fluid $\left(\mathrm{Wm}^{-1} \mathrm{~K}^{-1}\right)$

$k_{n f} \quad$ Thermal conductivity of nanofluid $\left(\mathrm{Wm}^{-1} \mathrm{~K}^{-1}\right)$

$k_{s} \quad$ Thermal conductivity of nanoparticles $\left(\mathrm{Wm}^{-1} \mathrm{~K}^{-1}\right)$

$M^{2} \quad$ Magnetic parameter $\left(\sigma_{f} B_{0}^{2} v_{f} / \rho_{f} U_{0}^{2}\right)$

$\operatorname{Pr} \quad$ Prandtl number $\left(\left(\rho v c_{p}\right)_{f} / k_{f}\right)$

$q_{r}^{\prime} \quad$ Radiative heat flux $\left(\mathrm{W} \mathrm{m}^{-2}\right)$

$T_{r} \quad$ Thermal radiation parameter (16 $\left.\sigma^{*} \delta_{\infty}^{\prime 3} / 3 k^{*} k_{f}\right)$

$u^{\prime} \quad$ Nanofluid velocity in $x^{\prime}$ direction $(\mathrm{m} / \mathrm{s})$

\section{Greek symbols}

$\beta_{f} \quad$ Thermal expansion coefficient of base fluid $\left(\mathrm{K}^{-1}\right)$

$\beta_{n f} \quad$ Thermal expansion coefficient of nanofluid $\left(\mathrm{K}^{-1}\right)$

$\beta_{s} \quad$ Thermal expansion coefficient of nanoparticle $\left(\mathrm{K}^{-1}\right)$

$\delta^{\prime} \quad$ Temperature of nanofluid (K) 
$\mu_{f} \quad$ Viscosity of base fluid $\left(\mathrm{kgm}^{-1} \mathrm{~s}^{-1}\right)$

$\mu_{n f} \quad$ Dynamic viscosity of nanofluid $\left(\mathrm{kgm}^{-1} \mathrm{~s}^{-1}\right)$

$\phi \quad$ Solid volume fraction of nanoparticle

$\rho_{f} \quad$ Density of base fluid $\left(\mathrm{kgm}^{-3}\right)$

$\rho_{n f} \quad$ Density of nanofluid $\left(\mathrm{kgm}^{-3}\right)$

$\rho_{s} \quad$ Density of nanoparticle $\left(\mathrm{kgm}^{-3}\right)$

$\left(\rho c_{p}\right)_{f} \quad$ Heat capacitance of base fluid

$\left(\rho c_{p}\right)_{n f} \quad$ Heat capacitance of nanofluid

$\left(\rho c_{p}\right)_{s} \quad$ Heat capacitance of nanoparticle

$\sigma^{*} \quad$ Stefan-Boltzmann constant $(5.67 \times$ $10^{-8} \mathrm{~W} / \mathrm{m}^{2} \mathrm{~K}^{4}$ )

$\sigma_{f} \quad$ Electrical conductivity of base fluid $\left(\mathrm{s}^{3} \mathrm{~A}^{2} \mathrm{~m}^{-3} \mathrm{~kg}^{-1}\right)$

$\sigma_{n f} \quad$ Electrical conductivity of nanofluid $\left(\mathrm{s}^{3} \mathrm{~A}^{2} \mathrm{~m}^{-3} \mathrm{~kg}^{-1}\right)$

$\sigma_{s} \quad$ Electrical conductivity of nanoparticle $\left(\mathrm{s}^{3} \mathrm{~A}^{2} \mathrm{~m}^{-3} \mathrm{~kg}^{-1}\right)$

\section{References}

1. Choi, S.U.S. "Enhancing thermal conductivity of fluids with nanoparticles, developments and applications of non-Newtonian flows", ASME FED 231/MD, 66, pp. 99-105 (1995).

2. Wang, X-Q. and Majumdar, A.S. "A review on nanofluids-Part I: Theoretical and numerical investigations", Braz. J. Chem. Eng., 25(4), pp. 613-630 (2008).

3. Eastman, J.A., Choi, S.U.S., Li, S., Thompson, L.J., and Lee, S. "Enhanced thermal conductivity through the development of nanofluids", In Nanophase and Nanocomposite Materials II, Materials Research Society, S. Komarneni, J.C. Parker, H.J. Wollenberger, Eds., Pittsburgh (1997).

4. Choi, S.U.S., Zhang, Z.G., Yu, W., Lockwood, F.E., and Grulke, E.A. "Anomalously thermal conductivity enhancement in nanotube suspensions", Appl. Phys. Letters, 79, pp. 2252-2254 (2001).

5. Keblinski, P., Phillpot, S.R., Choi, S.U.S., and Eastman, J.A. "Mechanism of heat flow is suspensions of nano-sized particles (nanofluids)", Int. J. Heat Mass Transf., 42, pp. 855-863 (2002).

6. Buongiorno, J. "Convective transport in nanofluids", J. Heat Transf., 128, pp. 240-250 (2006).

7. Jang, S.P. and Choi, S.U.S. "Effects of various parameters on nanofluid thermal conductivity", J. Heat Transf., 129, pp. 617-623 (2007).

8. Daungthongsuk, W. and Wongwises, S. "A critical review of convective heat transfer nanofluids", Renew. Sustain. Energy Reviews, 11, pp. 797-817 (2007).

9. Seyyedi, S.M., Bararnia, H., Ganji, D.D., GorjiBandpy, M., and Soleimani, S. "Numerical investigation of the effect of a splitter plate on forced convection in a two dimensional channel with an inclined square cylinder", Int. J. Thermal Sci., 61(0), pp. 1-14 (2012).

10. Sheikholeslami, M., GorjiBandpy, M., and Ganji, D.D. "Natural convection in a nanofluid filled concentric annulus between an outer square cylinder and an inner elliptic cylinder", Scientia Iranica B, 20(4), pp. 12411253 (2013).

11. Rashidi, M.M., Momoniat, E., Ferdows, M., and Basiriparsa, A. "Lie group solution for free convective flow of a nanofluid past a chemically reacting horizontal plate in a porous media", Mathematical Prob. Eng. (2014). (Article ID 239082)

12. Garoosi, F., Bagheri, G., and Rashidi, M.M. "Two phase simulation of natural convection and mixed convection of the nanofluid in a square cavity", Powder Tech., 275, pp. 239-256 (2015).

13. Garoosi, F., Rohani, B., and Rashidi, M.M. "Two phase mixture modeling of mixed convection of nanofluids in a square cavity with internal and external heating", Powder Tech., 275, pp. 304-321 (2015).

14. Rahman, S.U., Ellahi, R., Nadeem, S., and Zaigham Zia, Q.M. "Simultaneous effects of nano-particles and slip on Jeffrey fluid through tapered artery with mild stenosis", J. Molecular Liquids, 218, pp. 484-493 (2016).

15. Ellahi, R., Hassan, M., and Zeeshan, A. "Aggregation effects on water base nano fluid over permeable wedge in mixed convection", Asia-Pacific J. Chem. Eng., 11(2), pp. 179-186 (2016).

16. Ellahi, R., Zeeshan, A., and Hassan, M. "Particle shape effects on marangoni convection boundary layer flow of a nanofluid", Int. J. Num. Methods Heat Fluid Flow, 26(7), pp. 2160-2174 (2016).

17. Hamad, M.A.A. and Pop, I. "Unsteady MHD free convection flow past a vertical permeable flat plate in a rotating frame of reference with constant heat source in a nanofluid", Heat Mass Transf., 47, pp. 1517-1524 (2011).

18. Chamkha, A.J. and Aly, A.M. "MHD free convection flow of a nanofluid past a vertical plate in the presence of heat generation or absorption effects", Chem. Eng. Comm., 198, pp. 425-441 (2011).

19. Sheikholeslami, M., Hatami, M., and Ganji, D.D. "Analytical investigation of MHD nanofluid flow in a semiporous channel", Powder Tech., 246, pp. 327-336 (2013).

20. Das, K. "Flow and heat transfer characteristics of nanofluids in a rotating frame", Alexandria Eng. J., 53, pp. 757-766 (2014).

21. Sheikholeslami, M., Gorji Bandpy, M., Ellahi, R., and Zeeshan, A. "Simulation of MHD CuO-water nanofluid flow and convective heat transfer considering Lorentz forces", J. Magnetism Magnetic Materials, 369, pp. 69-80 (2014).

22. Sheikholeslami, M., Gorji Bandpy, M., and Ganji, D.D. "MHD free convection in an eccentric semiannulus filled with nanofluid", J. Taiwan Inst. Chem. Engineers, 45, pp. 1204-1216 (2014). 
23. Sheikholeslami, M. and Ganji, D.D. "Magnetohydrodynamic flow in a permeable channel filled with nanofluid", Scientia Iranica B, 21(1), pp. 203-212 (2014).

24. Nandkeolyar, R., Kameswaran, P.K., Shaw, S., and Sibanda, P. "Heat transfer on nanofluid flow with homogeneous-heterogeneous reactions and internal heat generation", J. Heat Transf., 136, pp. 122001-1 (2014).

25. Reddy, P.S. and Chamkha, A.J. "Influence of size, shape, type of nanoparticles, type and temperature of the base fluid on natural convection MHD of nanofluids", Alexandria Eng. J., 55, pp. 331-341 (2016).

26. Mahmoudi, A., Mejri, I., Abbassi, M.A., and Omri, A. "Analysis of MHD natural convection in a nanofluidfilled open cavity with non uniform boundary condition in the presence of uni-form heat generation/absorption", Powder Tech., 269, pp. 275-289 (2015).

27. Ellahi, R. "The effects of MHD and temperature dependent viscosity on the flow of non-Newtonian nanofluid in a pipe: Analytical solutions", Appl. Math. Modelling, 37(3), pp. 1451-1457 (2013).

28. Hayat, T., Muhammad, T., Qayyum, A., Alsaedi, A., and Mustafa, M. "On squeezing flow of nanofluid in the presence of magnetic field effects", J. Molecular Liquids, 213, pp. 179-185 (2016).

29. Dhanai, R., Rana, P., and Kumar, L. "MHD mixed convection nanofluid flow and heat transfer over an inclined cylinder due to velocity and thermal slip effects: Buongiorno's model", Powder Tech., 288, pp. 140-150 (2016).

30. Turkyilmazoglu, M. and Pop, I. "Heat and mass transfer of unsteady natural convection flow of some nanofluids past a vertical infinite flat plate with radiation effect", Int. J. Heat Mass Transf., 59, pp. 167-171 (2013).

31. Rashidi, M.M., Ganesh, N.V., Abdul Hakeem, A.K., and Ganga, B. "Buoyancy effect on MHD flow of nanofluid over a stretching sheet in the presence of thermal radiation", J. Molecular Liquids, 198, pp. 234238 (2014).

32. Haq, R.U., Nadeem, S., Khan, Z.H., and Akbar, N.S. "Thermal radiation and slip effects on MHD stagnation point flow of nanofluid over a stretching sheet", Physica E, 65, pp. 17-23 (2015).

33. Das, S. and Jana, R.N. "Natural convective magnetonanofluid flow and radiative heat transfer past a moving vertical plate", Alexandria Eng. J., 54, pp. 55-64 (2015).

34. Das, S., Jana, R.N., and Chamkha, A.J. "Magnetohydrodynamic free convective boundary layer flow of nanofluids past a porous plate in a rotating frame", $J$. Nanofluids, 4, pp. 176-186 (2015).

35. Sheikholeslami, M., Ganji, D.D., Javed, M.Y., and Ellahi, R. "Effect of thermal radiation on magneto- hydrodynamics nanofluid flow and heat transfer by means of two phase model", J. Magnetism Magnetic Materials, 374, pp. 36-43 (2015).

36. Sheikholeslami, M., Ganji, D.D., and Rashidi, M.M. "Ferrofluid flow and heat transfer in a semi annulus enclosure in the presence of magnetic source considering thermal radiation", J. Taiwan Inst. Chem. Engineers, 47, pp. 6-17 (2015).

37. Ellahi, R., Hassan, M., and Zeeshan, A. "Shape effects of nanosize particles in $\mathrm{Cu}-\mathrm{H}_{2} \mathrm{O}$ nanofluid on entropy generation", Int. J. Heat Mass Transf., 81, pp. 449-456 (2015).

38. Zeeshan, A., Majeed, A., and Ellahi, R. "Effect of magnetic dipole on viscous ferrofluid past a stretching surface with thermal radiation", J. Molecular Liquids, 215, pp. 549-554 (2016).

39. Das, S., Jana, R.N., and Makinde, O.D. "Transient natural convection in a vertical channel filled with nanofluids in the presence of thermal radiation", Alexandria Eng. J., 55, pp. 253-262 (2016).

40. Das, S., Jana, R.N., and Makinde, O.D. "Magnetohydrodynamic free convective flow of nanofluids past an oscillating porous flat plate in a rotating system with thermal radiation and hall effects", J. Mech., 32(02), pp. $197-210$ (2016).

41. Chandran, P., Sacheeti, N.C., and Singh, A.K. "Natural convection near a vertical plate with ramped wall temperature", Heat Mass Transf., 41, pp. 459-464 (2005).

42. Seth, G.S., Ansari, M.S. and Nandkeolyar, R. "MHD natural convection flow with radiative heat transfer past an impulsively moving plate with ramped wall temperature", Heat Mass Transf., 47, pp. 551-561 (2011).

43. Seth, G.S., Hussain, S.M., and Sarkar, S. "Hydromagnetic natural convection flow with radiative heat transfer past an accelerated moving vertical plate with ramped temperature through a porous medium", $J$. Porous Media, 17(1), pp. 67-79 (2014).

44. Seth, G.S., Sarkar, S., Hussain, S.M., and Mahato, G.K. "Effects of hall current and rotation on hydromagnetic natural convection flow with heat and mass transfer of a heat absorbing fluid past an impulsively moving vertical plate with ramped temperature", $J$. Appl. Fluid Mech., 8(1), pp. 159-171 (2015).

45. Nandkeolyar, R., Seth, G.S., Makinde, O.D., Sibanda, P., and Ansari, M.S. "Unsteady hydromagnetic natural convection flow of a dusty fluid past an impulsively moving vertical plate with ramped temperature in the presence of thermal radiation", ASME J. Appl. Mech., 80, pp. 061003-(1-9) (2013).

46. Hussain, S.M., Jain, J., and Seth, G.S. "Hall effects on MHD natural convection flow with heat and mass transfer of heat absorbing and chemically reacting fluid 
past a vertical plate with ramped temperature and ramped surface concentration", Bul. Chem. Comm., 48(4), pp. 659-670 (2016).

47. Hussain, S.M., Jain, J., Seth, G.S., and Rashidi, M.M. "Free convective heat transfer with hall effects, heat absorption and chemical reaction over an accelerated moving plate in a rotating system", J. Magnetism Magnetic Materials, 422, pp. 112-123 (2017).

48. Nandkeolyar, R., Das, M., and Pattnayak, H. "Unsteady hydromagnetic radiative flow of a nanofluid past a flat plate with ramped temperature", J. Orissa Mathematical Soc., 32, pp. 15-30 (2013).

49. Khalid, A., Khan, I., and Shafie, S. "Exact solutions for free convection flow of nanofluids with ramped wall temperature", The Europ. Physical J.-Plus, 130, p. 57 (2015).

50. Ghosh, S.K. and Bhattacharjee, P.K. "Hall effects on steady hydromagnetic flow in a rotating channel in the presence of an inclined magnetic field", Czech. J. Phys., 50(6), pp. 759-767 (2000).

51. Ghosh, S.K., Bég, O.A., and Narahari, M. "A study of unsteady rotating hydromagnetic free and forced convection in a channel subject to forced oscillation under an oblique magnetic field", J. Appl. Fluid Mech., 6(2), pp. 213-227 (2013).

52. Nandkeolyar, R. and Das, M. "MHD free convective radiative flow past a flat plate with ramped temperature in the presence of inclined magnetic field", Comp. Appl. Math., 34, pp. 109-123 (2015).

53. Oztop, H.F. and Abu-Nada, E. "Numerical study of natural convection in partially heated rectangular enclosures filled with nanofluids", Int. J. Heat Fluid Flow, 29(5), pp. 1326-1336 (2008).

54. Turkyilmazoglu, M. "Unsteady convection flow of some nanofluids past a moving vertical flat plate with heat transfer", J. Heat Transf., 136, pp. 031704-031704-7 (2013).

55. Kakac, S. and Pramuanjaroenkij, A. "Review of convective heat transfer enhancement with nanofluids", Int. J. Heat Mass Transf., 52, pp. 3187-3196 (2009).

56. Rosseland, S. Astrophysik und Atom-Theoretische Grundlagen, Springer-Verlag, Berlin (1931).

\section{Appendix A}

$$
\begin{gathered}
f_{1}\left(\lambda_{1}, \lambda_{2}, \lambda_{3}, \lambda_{4}, \lambda_{5}\right)=\left\{\frac{1}{\lambda_{4}}+\left(\lambda_{5}+\frac{\lambda_{1}}{2} \sqrt{\frac{\lambda_{2}}{\lambda_{3}}}\right)\right\} \\
e^{\lambda_{1} \sqrt{\lambda_{2} \lambda_{3}}} \operatorname{erfc}\left(\frac{\lambda_{1}}{2} \sqrt{\frac{\lambda_{2}}{\lambda_{5}}}+\sqrt{\lambda_{3} \lambda_{5}}\right) \\
+\left\{\frac{1}{\lambda_{4}}+\left(\lambda_{5}-\frac{\lambda_{1}}{2} \sqrt{\frac{\lambda_{2}}{\lambda_{3}}}\right)\right\} \\
\quad \times e^{-\lambda_{1} \sqrt{\lambda_{2} \lambda_{3}}} \operatorname{erfc}\left(\frac{\lambda_{1}}{2} \sqrt{\frac{\lambda_{2}}{\lambda_{5}}}-\sqrt{\lambda_{3} \lambda_{5}}\right),
\end{gathered}
$$

$$
\begin{aligned}
& f_{2}\left(\lambda_{1}, \lambda_{2}, \lambda_{3}, \lambda_{4}, \lambda_{5}\right)=e^{\lambda_{1} \sqrt{\lambda_{2}\left(\lambda_{3}+\lambda_{4}\right)}} \\
& \operatorname{erfc}\left(\frac{\lambda_{1}}{2} \sqrt{\frac{\lambda_{2}}{\lambda_{5}}}+\sqrt{\left(\lambda_{3}+\lambda_{4}\right) \lambda_{5}}\right) \\
& +e^{-\lambda_{1} \sqrt{\lambda_{2}\left(\lambda_{3}+\lambda_{4}\right)}} \operatorname{erfc}\left(\frac{\lambda_{1}}{2} \sqrt{\frac{\lambda_{2}}{\lambda_{5}}}-\sqrt{\left(\lambda_{3}+\lambda_{4}\right) \lambda_{5}}\right), \\
& f_{3}\left(\lambda_{1}, \lambda_{2}, \lambda_{3}, \lambda_{4}\right)=\left\{\frac{1}{\lambda_{3}}+\left(\lambda_{4}+\frac{\lambda_{2} \lambda_{1}^{2}}{2}\right)\right\} \\
& \operatorname{erfc}\left(\frac{\lambda_{1}}{2} \sqrt{\frac{\lambda_{2}}{\lambda_{4}}}\right)-\lambda_{1} \sqrt{\frac{\lambda_{2} \lambda_{4}}{\pi}} e^{-\left(\lambda_{2} \lambda_{1}^{2}\right) /\left(4 \lambda_{4}\right)}, \\
& f_{4}\left(\lambda_{1}, \lambda_{2}, \lambda_{3}\right)=\left(\sqrt{\frac{\lambda_{1}}{\lambda_{2}}}+2 \lambda_{3} \sqrt{\lambda_{1} \lambda_{2}}\right) \\
& \left\{\operatorname{erfc}\left(\sqrt{\lambda_{2} \lambda_{3}}\right)-1\right\}-2 \sqrt{\frac{\lambda_{1} \lambda_{3}}{\pi}} e^{-\lambda_{2} \lambda_{3}} \\
& f_{5}\left(\lambda_{1}, \lambda_{2}, \lambda_{3}, \lambda_{4}\right)=\sqrt{\lambda_{1}\left(\lambda_{2}+\lambda_{3}\right)} \\
& \left\{\operatorname{erfc}\left(\sqrt{\left.\left(\lambda_{2}+\lambda_{3}\right) \lambda_{4}\right)}-1\right\}-\sqrt{\frac{\lambda_{1}}{\pi \lambda_{4}}} e^{-\left(\lambda_{2}+\lambda_{3}\right) \lambda_{4}} .\right.
\end{aligned}
$$

\section{Biographies}

Syed Modassir Hussain is working as a Senior Assistant Professor in the Depart-ment of Mathematics, OP Jindal University, Raigarh (C. G.), India. He received his $\mathrm{PhD}$ degree, with his dissertation entitled "Investigation of Some Problems of Fluid Flow and Heat Transfer in Magne-tohydrodynamics", from Indian Institute of Technology (ISM), Dhanbad, India. He has more than 7 years of experience in teaching and research. His topics of research are related to fluid dynamics, magnetohydrodynamics, and heat and mass transfer. He has published 17 research papers in the peer reviewed international journals of repute.

Jainendra Jain is a Professor in the Department of Applied Mathematics, Government Engineering College (GEC), Jagdalpur, Bastar (C.G.), India. He received his $\mathrm{PhD}$ in Mathematics from the School of Mathematics and Allied Sciences, Jiwaji University, Gwalior (M.P.), India. He has 18 years of experience in teaching and research. His current area of research studies includes fluid dynamics, magnetohydrodynamics, computational finance, and fixed point theory. He has more than 20 publications under his credit in journals of national/international repute.

Gauri Shanker Seth is a Senior Professor in the Department of Applied Mathematics, Indian Insti- 
tute of Technology (ISM), Dhanbad, India. He received his $\mathrm{PhD}$ degree in Mathematics from Indian Institute of Technology, Kharagpur, India. He has more than 35 years of experience in teaching and research. His current area of research studies includes fluid dynamics, magnetohydro-dynamics, and heat and mass transfer. He was Visiting Assistant Professor at University of Aden, Republic of Yemen, during the period of September 01, 1991 to August 31, 1993. He has published more than 120 research papers in national/international journals of repute well recognized by engineers and scientists throughout the world.

Mohammad Mehdi Rashidi is a Professor of Me- chanical Engineering at Tongji University, Shanghai, China. He has published 2 books: Advanced Engineering Mathematics with Applied Examples of MATHEMATICA Software (2007) (320 pages) (in Persian), and Mathematical Modelling of Nonlinear Flows of Micropolar Fluids (Germany, Lambert Academic Press, 2011). His works have been published in the Plos One, Energy, Computers and Fluids, Communications in Nonlinear Science and Numerical Simulation, and several other peer-reviewed international journals. He has published over 300 (225 of them are indexed in Scopus) journal articles and 45 conference papers. Professor Rashidi is a reviewer of several journals (over 160 refereed journals) and the editor of 50 international journals. 